\title{
Camera traps reveal overlap and seasonal variation in the diel activity of arboreal and semi-arboreal mammals
}

\author{
Ana Gracanin ${ }^{1}$ (I) $\cdot$ Katarina M. Mikac ${ }^{1}$
}

Received: 27 August 2021 / Accepted: 22 December 2021 / Published online: 24 February 2022

(c) The Author(s) 2022

\begin{abstract}
Our study aimed to investigate seasonal variation in the activity of arboreal and semi-arboreal mammals and investigate their overlap in temporal activity, as well temporal shifts in activity because of behavioural interference. In our camera trapping study in a fragmented landscape in south-eastern Australia, a total of ten arboreal and semi-arboreal species were found, with 35,671 independent observations recorded over 6517 camera trap nights. All species were found to be nocturnal; however, a notable number of daytime observations were made for several species (i.e. brown antechinus, Antechinus stuartii; sugar glider, Petaurus breviceps; bush rat, Rattus fuscipes; brown rat, Rattus norvegicus). Seasonal variations in diel activity were observed through an increase in crepuscular activity in spring and summer for antechinus, sugar gliders, brown rats, brushtail possums, Trichosurus vulpecula and ringtail possums, Pseudocheirus peregrinus. Diel activity overlap between species was high, that is $26 / 28$ species comparisons had overlap coefficients $(\Delta)>0.75$. The species pair with the least amount of overlap was between southern bobucks, Trichosurus cunninghami and brown antechinus $(\Delta 4=0.66)$. The species pair with the most overlap was between the native sugar glider and introduced brown rat $(\Delta 4=0.93)$. When comparing the activity of sugar gliders in sites with low and high abundance of brown rats, sugar gliders appear to shift their activity relative to the brown rats. Similarly, behavioural interference was also observed between antechinus and sugar gliders, and when comparing sites of low and high abundance of sugar glider, antechinus had a shift in activity. Our work provides some of the first quantification of temporal patterns for several of the species in this study, and the first for a community of arboreal and semi-arboreal mammals. Our results indicate that some shifts in behaviour are potentially occurring in response to behavioural interference, allowing for coexistence by means of temporal partitioning.
\end{abstract}

Keywords Tree-dwelling $\cdot$ Diel $\cdot$ Circadian $\cdot$ Season $\cdot$ Activity $\cdot$ Small mammal $\cdot$ Interference

\section{Introduction}

Animal behaviour as a function of activity across a $24 \mathrm{~h}$ period is fundamental to an animal's survival and fitness, as it enables an animal to obtain resources such as food, as well as mates, all while avoiding competitors, predators, and

Handling editor: Frank E. Zachos.

\section{Ana Gracanin}

anagracanin@outlook.com

$\triangle$ Katarina M. Mikac

kmikac@uow.edu.au

1 Centre for Sustainable Ecosystem Solutions, School of Earth, Atmospheric and Life Sciences, Faculty of Science, Medicine and Health, University of Wollongong, Wollongong, Australia unfavourable environmental conditions (Daan 1981; Kronfeld-Schor and Dayan 2003). The timing of activities has significant ecological implications, and can influence interspecific competition (Abu Baker and Brown 2014; Nguyen et al. 2020), abundance (Williams et al. 2017), plant-herbivore interactions (Yang and Rudolf 2010) and the dynamics of disease (Harvell et al. 2009; Altizer et al. 2011). Identifying factors that can change such behaviours has also shown to be important for species conservation (Kronfeld-Schor and Dayan 2003), particularly in response to human disturbances (Gaynor et al. 2018; Shamoon et al. 2018).

Knowledge about a mammal's temporal niche is important to understand ecological interactions (Halle and Stenseth 2012). Circadian (24 h) and seasonal patterns of activity are adaptive behaviours that allow mammals to effectively exploit their habitat and associated resources (Wu et al. 2018). Mammal diel activity patterns are categorised as 
nocturnal, diurnal, crepuscular or cathemeral (Bennie et al. 2014). These patterns of activity not only vary among species (Gómez et al. 2005; Caravaggi et al. 2018; Vazquez et al. 2019; Mori et al. 2021) but vary across latitudes and seasons (Ikeda et al. 2016). Many factors can influence activity, such as competition (Rychlik 2005), predator-prey relationships (Mori et al. 2020), temperature (Hanya et al. 2018), resource availability (Pereira 2010), moonlight (Huck et al. 2017) and precipitation (Suzuki and Ando 2019). In addition, individuals within species may also show different patterns of activity rhythms in response to different environmental conditions (Hertel et al. 2017). For ecologically similar or sympatric species, coexistence amongst species is often determined by the important role of competition (Hughes et al. 1994; Cunningham et al. 2019). Species often mitigate competition by partitioning resources in three dimensions (space, time, and resource-selection), resulting in niche differentiation (Schoener 1974). Investigating species' niche differentiation highlights the capacity of species to coexist which is important for biodiversity conservation, particularly in the context of understanding the effect of anthropogenic disturbances such as introduced species (Harrington et al. 2009; HilleRisLambers et al. 2012; Carscadden et al. 2020; Pascual-Rico et al. 2020; Gaudiano et al. 2021; Andreoni et al. 2021).

Interference competition occurs when two species share a resource, and one of the species is dominant and displays antagonistic behaviours to obtain a resource (Case and Gilpin 1974). As an active form of competition, it often results in the more subordinate species realising a cost, either through a loss of space (Ziv et al. 1993), time (Saleni et al. 2007) or a loss of life (Berger and Gese 2007). Through altering the timing of foraging activities, species can reduce interspecific contact and thus facilitate temporal niche partitioning (Carothers and Jaksić 1984; Hayward and Slotow 2009). Studies have found that aggression between species can influence individuals to change their behaviours to reduce chance of interactions (Wrobell et al. 1980; Ping et al. 2011; Barrull et al. 2014) though the presence of scent can also mediate changes in behaviour spatially and temporally (Dickman 1991; Mukherjee et al. 2009; Leo et al. 2015). Our study offers a unique opportunity to investigate this effect of behavioural interference, as aggression and territorial (scent marking) behaviours for select species were observed in our study.

Mammalian activity patterns and behaviours can be quantified and described through direct observations (Belovsky and Slade 1986; Mutschler et al. 1998; Yang et al. 2002; Gashe and Yihune 2020), constant monitoring of live traps (Rychlik 2005) and through tracking devices (Ables 1969; Roth 1983; Bonnot et al. 2020). These methods, however, are resource- and time-intensive and can have animal welfare implications; thus, the application of camera trapping has received much use in recent times (Bridges and Noss 2011; Burton et al. 2015; Caravaggi et al. 2017). Camera trapping allows for high volumes of data to be collected, with minimal animal and habitat disturbance, in exchange for relatively low effort and cost (Burton et al. 2015; Caravaggi et al. 2017). Camera trapping has been readily applied to the study of large charismatic mammals (Burton et al. 2015). However, the limited focal range of most motion sensor camera models has precluded their use in small mammal studies because images cannot capture enough detail for accurate species identification (Meek et al. 2013; Potter et al. 2019). Recent novel methods have allowed for small mammals to be camera trapped (McCleery et al. 2014; Gray et al. 2017; Hobbs and Brehme 2017; Gracanin et al. 2018; Mos and Hofmeester 2020). Nevertheless, a gap remains in the published literature that examines small mammal behaviour using camera traps. A number of researchers have used camera traps to study large mammal temporal niches (RomeroMunoz et al. 2010; Šprem et al. 2015; Porfirio et al. 2017; Shamoon et al. 2018; Vazquez et al. 2019; Marinho et al. 2020; Kavčić et al. 2021), but few have studied the details of activity patterns in sympatric small mammal species (Halle and Stenseth 2012). This limited study is also especially true for obligate arboreal species that are cryptic, as they spend their entire lives in the canopy, and that are nocturnal (Kays and Allison 2001; Moore et al. 2021). Thus, there have been very few examinations of activity patterns in arboreal and semi-arboreal mammals (e.g. Oliveira-Santos et al. 2008; Suzuki and Ando 2017). Through the close examination of activity patterns and temporal niche partitioning between species, their co-existence can be examined (Frey et al. 2017; Mori et al. 2019; Lear et al. 2021). Importantly, understanding these processes for arboreal mammals can now be undertaken using camera trapping (Moore et al. 2021).

The use of camera trapping for systematic studies of activity and temporal niche overlap has grown greatly over the past two decades (Turner 1984; Bridges and Noss 2011; Caravaggi et al. 2017; Agha et al. 2018; Delisle et al. 2021). Lashley et al. (2018) found that, with a sample size of at least 20-30 independent detection events from camera trapping, curves of species activity are comparable to those obtained through radio-tracking. Thus by combining the aforementioned with novel camera trapping methods for accurate small mammal identification (Gracanin et al. 2018), here we provide unique insight into Australian arboreal mammalian assemblages and their activity patterns, and explore the effect of interference behaviours.

Our study involved a long-term camera trap survey using selfie traps placed in trees, in a fragmented landscape in south-eastern Australia, to collect data on arboreal species ranging from $40 \mathrm{~g}$ eastern pygmy possums, Cercartetus nanus to $4.2 \mathrm{~kg}$ southern bobucks, Trichosurus cunninghami. The aims of our study were to: (1) document the 
seasonal variation in diel activity patterns of arboreal and semi-arboreal mammals; (2) compare the overlap in activity between each species pair; and (3) identify shifts in activity that may be occurring because of behavioural interference. It was hypothesised that all species would be predominately nocturnal, with shifts in crepuscular peaks (in response to seasons or the timing of breeding during the year). This is particularly relevant for the semelparous brown antechinus. It was also hypothesised that species would shift their timing or intensity of activity in response to interference behaviours such as aggression. This study not only provides some of the first basic biological data for circadian activity of the species studied, but also significant insights into potential temporal niche partitioning as driven by behavioural interference.

\section{Methods}

\section{Study area}

This study was part of a broader project investigating arboreal marsupial abundance and distribution within a fragmented landscape, surrounding the township of Berry
( $\left.34^{\circ} 46^{\prime} 32.8^{\prime \prime} \mathrm{S} 150^{\circ} 41^{\prime} 56.0^{\prime \prime} \mathrm{E}\right)$ located approximately $100 \mathrm{~km}$ south of Sydney, Australia. The study design focused on four major areas of interest as part of informing the Berry Bush Links wildlife corridor (GER 2021), with 18 long-term monitoring sites established and set to monitor for one year (Fig. 1). The sites consisted of a mix of private and public estate. Habitat forms varied between eucalyptus forests, swamp edges and creek lines dominated by casuarina, and subtropical rainforest of the Illawarra Escarpment.

\section{Camera trapping}

Eighteen cameras were placed randomly throughout the landscape, spaced at least $500 \mathrm{~m}$ apart ensuring independence between sites (Fig. 1). Camera trapping targeted small mammals using the selfie trap method (Gracanin et al. 2018). Selfie traps were placed on platforms positioned two metres up trees, with the entrance facing the tree trunk (Fig. 2).

Cameras were serviced and bait replenished on average at a fortnightly basis (between 19/11/2019-30/11/2020). Randomisation occurred of whether bait placed out or not, or if an olfactory cue of cotton wool soaked in vanilla essence was used. Randomisation also occurred as to whether honey
Fig. 1 Location of long-term monitoring sites $(n=18)$ within the study landscape. Four major areas of interest were targeted, denoted as Areas 1 to 4 (A1, $\mathrm{A} 2, \mathrm{~A} 3$ and $\mathrm{A} 4)$ in site names

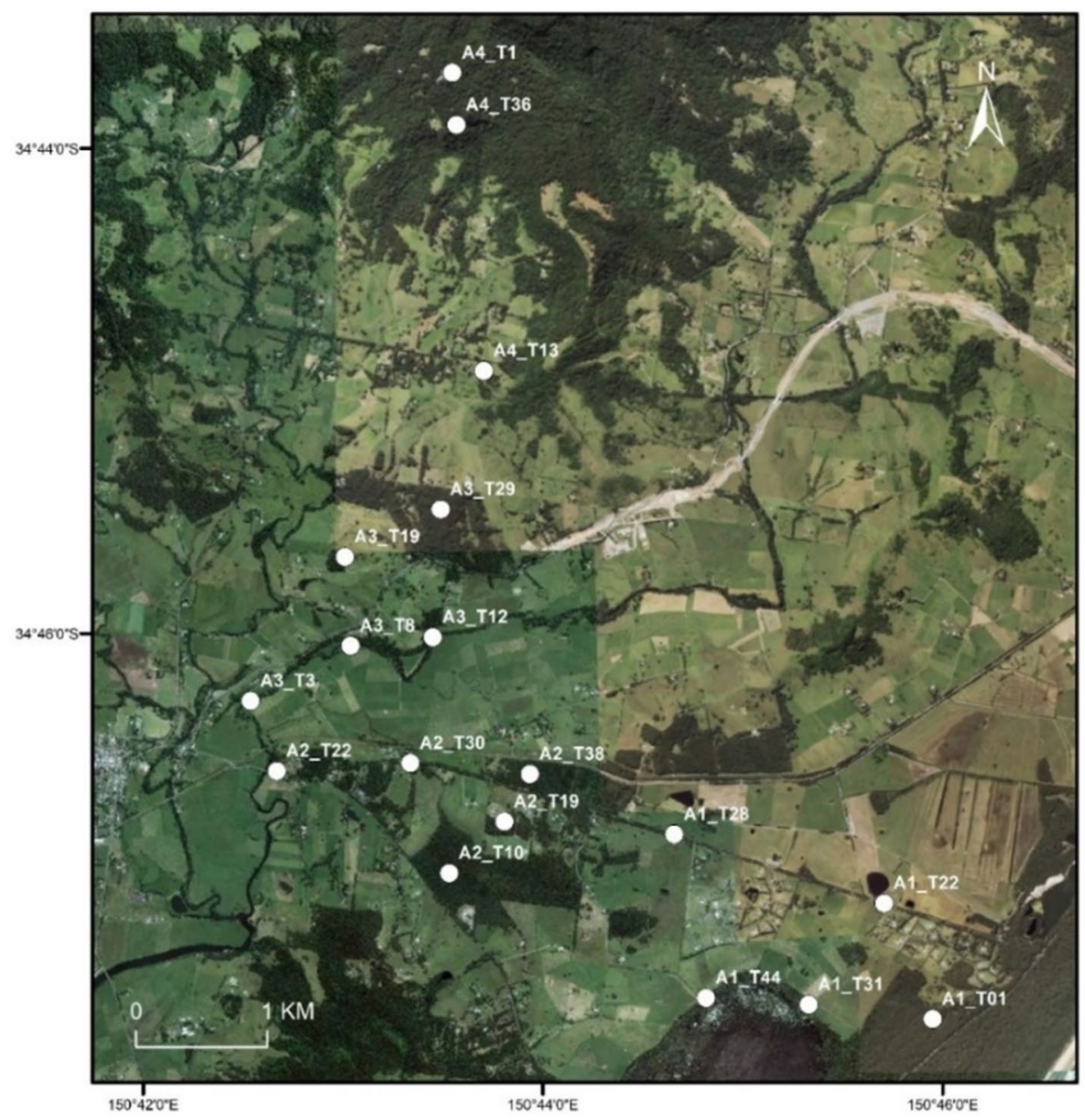




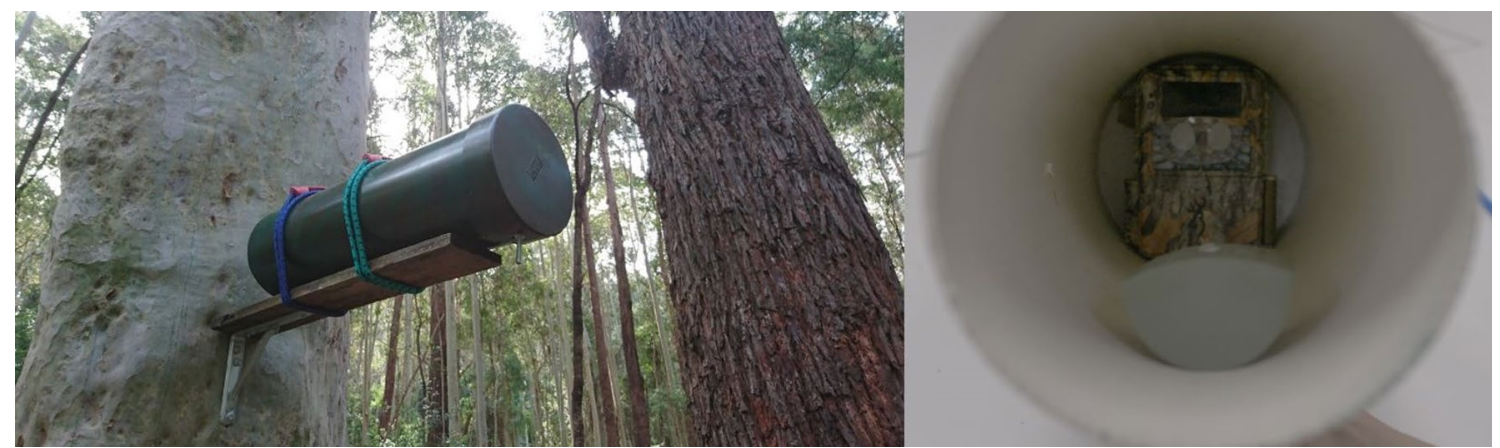

Fig. 2 Exterior view of the selfie trap method (left) and interior view of camera and bait holder (right), used to target small and arboreal mammals in this study

water mixture was sprayed up and down trees and surrounding foliage. This randomisation occurred to reduce the habituation of species to scheduled baits. Though bait can overinflate detections and lead to bias, the present study was only concerned with activity, and, hence, the time of detection of any animal was assumed to be representative of the species as a whole (Caravaggi et al. 2018). The schedule of baiting/ servicing cameras, and camera operation times, is outlined in Online Appendix 1.

Cameras were set to record a $20 \mathrm{~s}$ video, with a $10 \mathrm{~min}$ delay. Animals seen in the footage were identified to the species and sorted by site. The software BulkFileChanger (Sofer 2021) was then used to collect the date and time for every video file in a batch process. Observations of gliders and possums sleeping inside the selfie traps during the day were removed.

\section{Data analysis}

All statistical analyses were conducted using R software version 4.0.2 ( $\mathrm{R}$ Core Team 2021). The date and time data (observations between 1/12/2019 and 30/11/2020 selected) were transformed into solar time to reduce the bias associated with local time (Vazquez et al. 2019), using the 'Activity' package (Rowcliffe et al. 2014). Detections for each species were considered independent if taken at intervals of greater than one hour (Porfirio et al. 2017; Li et al. 2020; Marinho et al. 2020). This dataset with observations separated by one hour was extracted using the assess temporal independence function in the R package 'camtrapR' (Niedballa et al. 2016).

\section{Season variation in diel activity}

Seasonal variation in diel activity for each species was estimated using nonparametric kernel density estimates (with 95\% confidence intervals obtained from 1000 bootstrap samples). Average proportions of diel activity were calculated for each species, for each season.

\section{Comparisons in activity overlap}

Tests for temporal segregation between each species pair were calculated on annual datasets using non-parametric kernel density functions to estimate activity overlap coefficients which ranged from 0 (no overlap) -1 (complete overlap in temporal activity). The $95 \%$ confidence intervals of overlap coefficients were obtained through 1000 bootstrap samples. As per Ridout and Linkie (2009), the coefficient $\Delta 1$ was only used for small samples ( $<75$ records) and the coefficient $\Delta 4$ was used for large samples ( $>75$ records). Overlap analyses were undertaken using the R package 'Overlap' (Ridout and Linkie 2009). As $\Delta$ coefficients are a descriptive measure of overlap, the Mardia-Watson-Wheeler test was performed to test for homogeneity on two samples using the R package 'Circular' (Agostinelli and Lund 2017).

\section{Behavioural interference}

As observations of antagonistic behaviour between sugar gliders and antechinus were found on camera, we investigated the effect of high sugar glider abundance on antechinus behaviour. Sites were separated into two categories: low $(n=7)$ and high $(n=8)$. For low sites, average glider observations per camera trap night ranged between 0.04 and 1.63. For high glider abundance sites, glider observations per camera trap night ranged between 3.83 and 5.99. The annual diel activities for antechinus in low and high glider abundance sites were subject to an overlap analysis (as per overlap analyses described above).

The same antagonistic behaviour was observed between brown rats and sugar gliders. However, on multiple occasions, sugar gliders and brown rats were observed tolerating each other's presence (i.e., instances of occurring together harmoniously). The rats on camera were sub-adults and 
equal in size to the adjacent glider on camera. To compare the effect of the introduced brown rat on sugar gliders, a similar analysis was undertaken as above with sugar glider abundance effects on antechinus activity. Three low brown rat abundance sites were selected, ranging from 0.09 to 0.42 observations of brown rats per camera trap night. The three high brown rat abundance sites ranged from 1.97 to 3.29 observations of brown rats per camera trap night.

\section{Results}

\section{Overall species detection}

In total, ten species were detected on camera with the target species the sugar glider detected the most, and the feather-tailed glider the least (Table 1). In total, 59,996 videos were recorded over 6517 camera trap nights. Of these video detections, 35,671 were deemed independent observations. During spring, the most species were detected, and in winter, the least numbers were detected (Table 1). Very few observations for feather-tailed gliders and house mice were observed (Table 1) and thus these species were excluded from further analyses.

The average proportions of time spent active in a diel cycle, were highest for the brushtail possum (47\%) and brown rat (42\%) across all seasons (Table 2). For the sugar glider, activity was highest in summer (38\%) and lowest in winter (28\%) (Table 2). For brown antechinus and ringtail possum, the most activity was recorded in winter $(41 \%$ and $44 \%$ respectively). The highest amount of activity for bush rats was recorded in spring (41\%). Eastern pygmy possums had too few observations to warrant analysis across all seasons, and in total had an annual activity level of $34 \%$. The southern bobuck had the least recorded diel activity, overall, only being active $27 \%$ of the time during a $24-\mathrm{h}$ period.
Table 1 Number of camera trap observations (separated by $1 \mathrm{~h})$ for ten arboreal and semiarboreal species detected and surveyed in the study landscape

\begin{tabular}{lrrrrr}
\hline Species & Annual & Summer & Autumn & Winter & Spring \\
\hline Feather-tailed glider (Acrobates pygmaeus) & 2 & 0 & 0 & 0 & 2 \\
Brown antechinus (Antechinus stuartii) & 12,250 & 3048 & 4106 & 2870 & 2226 \\
Eastern pygmy possum (Cercartetus nanus) & 68 & 4 & 1 & 0 & 63 \\
House mouse (Mus musculus) & 19 & 0 & 13 & 4 & 2 \\
Sugar glider (Petaurus breviceps) & 17,120 & 3471 & 3656 & 2834 & 7159 \\
Ringtail possum (Pseudocheirus peregrinus) & 144 & 30 & 12 & 49 & 53 \\
Bush rat (Rattus fuscipes) & 472 & 21 & 106 & 65 & 280 \\
Brown rat (Rattus norvegicus) & 5114 & 1498 & 1004 & 792 & 1820 \\
Southern bobuck (Trichosurus cunninghami) & 204 & 50 & 36 & 65 & 53 \\
Brushtail possum (Trichosurus vulpecula) & 278 & 94 & 32 & 65 & 87 \\
Total number of observations: & 35,671 & 8216 & 8966 & 6744 & 11,745 \\
\hline
\end{tabular}

For summer (December-January), there were 1613 camera-trap nights; autumn (March-May) had 1644 camera-trap nights; winter (June-August) had 1640 camera-trap nights and spring (September-November) had 1620 camera-trap nights

Table 2 Activity levels (0-1) of time spent active in a diel (24 h) cycle for nine arboreal and semi-arboreal species surveyed in the study landscape ( \pm standard error)

\begin{tabular}{|c|c|c|c|c|c|}
\hline Species & Annual & Summer & Autumn & Winter & Spring \\
\hline Brown antechinus (Antechinus stuartii) & $0.39 \pm 0.01$ & $0.28 \pm 0.01$ & $0.4 \pm 0.01$ & $0.41 \pm 0.02$ & $0.33 \pm 0.01$ \\
\hline Eastern pygmy possum (Cercartetus nanus) & $0.34 \pm 0.04$ & - & - & - & $0.38 \pm 0.04$ \\
\hline Sugar glider (Petaurus breviceps) & $0.35 \pm 0.01$ & $0.38 \pm 0.01$ & $0.35 \pm 0.01$ & $0.28 \pm 0.01$ & $0.33 \pm 0.01$ \\
\hline Ringtail possum (Pseudocheirus peregrinus) & $0.38 \pm 0.33$ & $0.22 \pm 0.05$ & $0.31 \pm 0.06$ & $0.44 \pm 0.06$ & $0.27 \pm 0.04$ \\
\hline Bush rat (Rattus fuscipes) & $0.30 \pm 0.02$ & $0.22 \pm 0.05$ & $0.37 \pm 0.04$ & $0.14 \pm 0.02$ & $0.41 \pm 0.02$ \\
\hline Brown rat (Rattus norvegicus) & $0.42 \pm 0.01$ & $0.39 \pm 0.02$ & $0.4 \pm 0.02$ & $0.34 \pm 0.02$ & $0.41 \pm 0.02$ \\
\hline Southern bobuck (Trichosurus cunninghami) & $0.27 \pm 0.02$ & $0.16 \pm 0.02$ & $0.35 \pm 0.05$ & $0.22 \pm 0.03$ & $0.23 \pm 0.04$ \\
\hline Brushtail possum (Trichosurus vulpecula) & $0.47 \pm 0.03$ & $0.42 \pm 0.05$ & $0.33 \pm 0.04$ & $0.33 \pm 0.04$ & $0.44 \pm 0.04$ \\
\hline
\end{tabular}

For summer (December-January), there were 1,613 camera-trap nights; autumn (March-May) had 1644 camera-trap nights; winter (JuneAugust) had 1640 camera-trap nights and spring (September-November) had 1620 camera-trap nights 

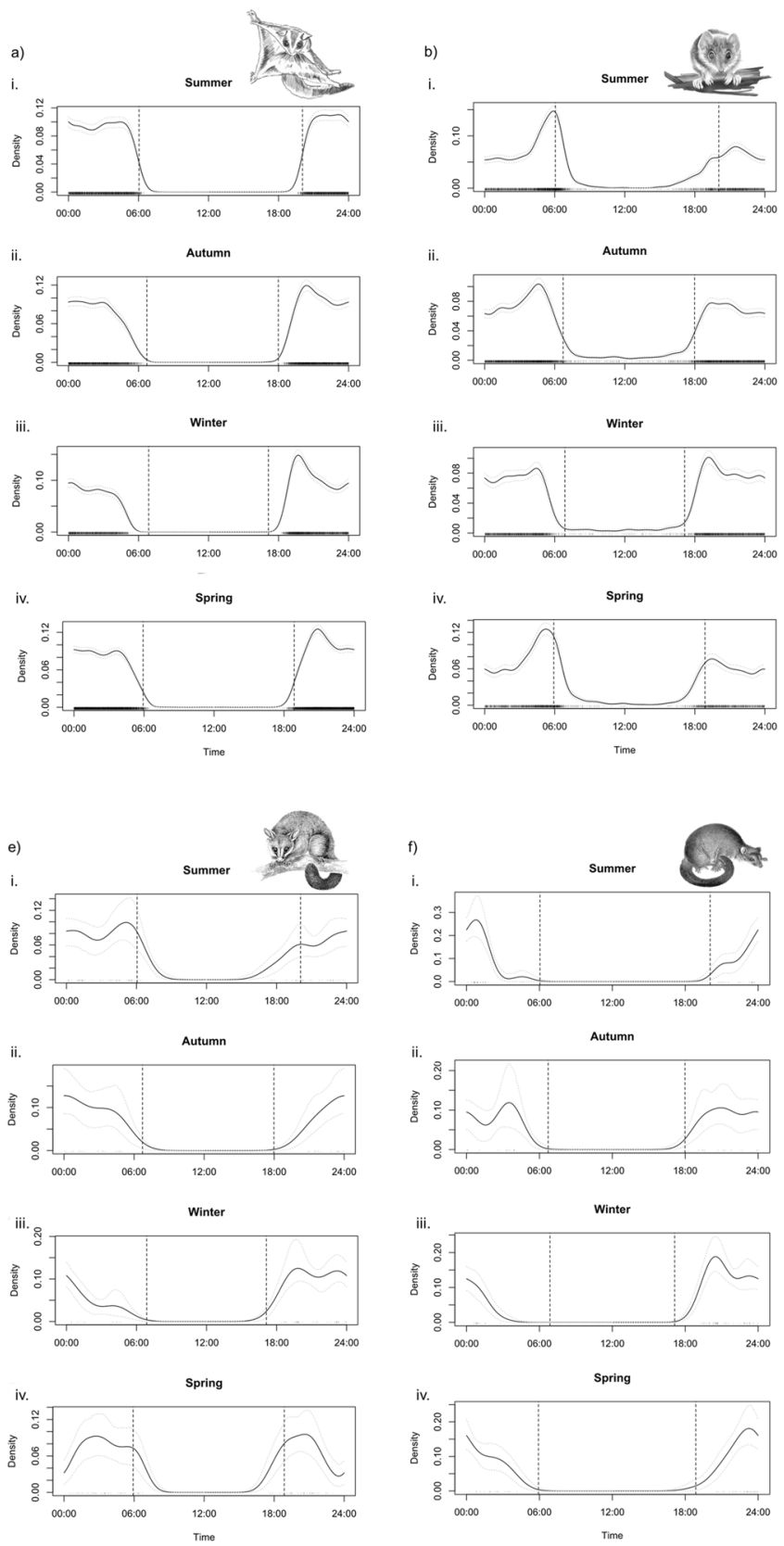

Fig. 3 Seasonal patterns of diel activity in seven species: a sugar gliders (Petaurus breviceps); b brown antechinus (Antechinus stuartii); $\mathbf{c}$ bush rats (Rattus fuscipes); d brown rats (Rattus norvegicus); e common brushtail possums (Trichosurus vulpecula); f southern bobucks (Trichosurus cunninghami); $\mathbf{g}$ common ringtail possums (Pseudocheirus peregrinus). Kernel density activity estimates ( $y$-axis) are shown with $95 \%$ confidence intervals (dotted grey lines). Tick
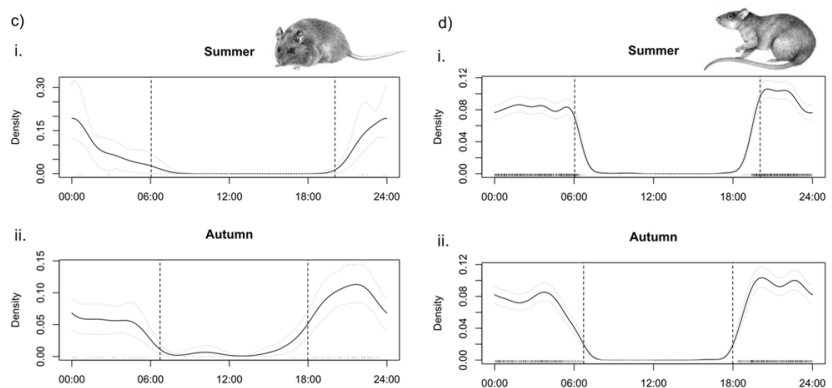

iii.

Winter

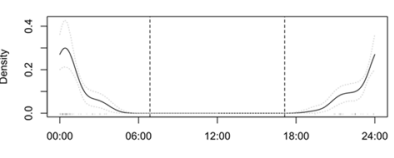

iii. Winter
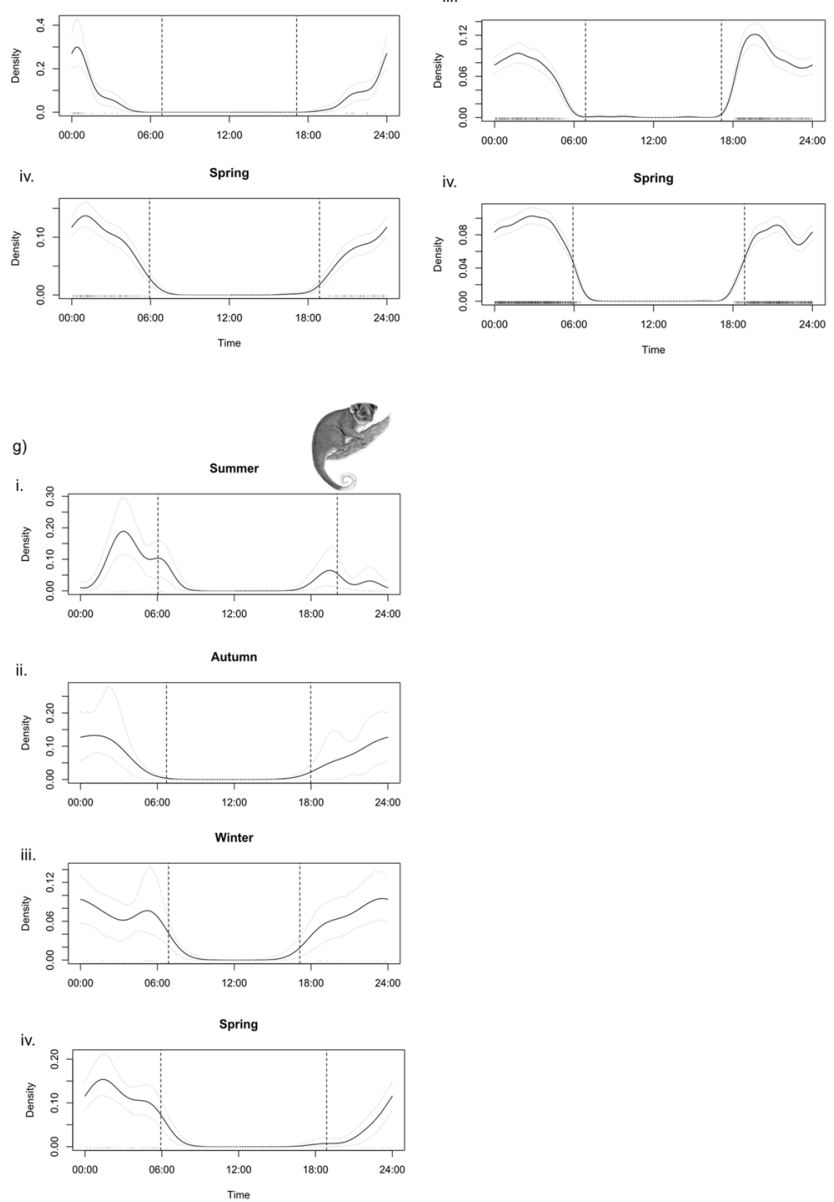

marks on the $x$-axis indicate times of independent observations used to estimate the activity pattern. Black dashed lines are average sunrise and sunset times, calculated for each season. Time depicted is in solar time. Illustration credits for first four images from left to right: Rocco Russo, Tracy MacVean, NSW NPWS, Lizzie Harper www.lizzieharp er.co.uk, last image; Elizabeth Ann Francis 


\section{Seasonal variation in activities}

Sugar glider activity was predominately nocturnal, with some activity occurring around twilight $( \pm 1 \mathrm{~h}$ at sunrise and sunset) and during the day (see black ticks of individual records on the $x$-axis; Fig. 3a). Sugar glider peaks in activity shifted throughout the year, with summer having relatively constant activity throughout the night and occurring one hour after sunset and ending one hour before sunrise (Fig. 3a). In autumn, activity peaked two hours after sunset around 20:00, and started to decrease after 03:00, approximately $3.5 \mathrm{~h}$ before sunrise. In winter, sugar glider activity peaked at 19:30, approximately $2.5 \mathrm{~h}$ after sunset. Activity remained relatively constant until 04:30, when activity began to sharply decline $2.5 \mathrm{~h}$ before sunrise. In spring, sugar gliders peaked in activity $1.5 \mathrm{~h}$ after sunset, at around 20:30, and declined in activity $2 \mathrm{~h}$ before sunrise at 04:00.

Antechinus activity varied greatly among seasons, with the majority of observations falling within nocturnal periods though many observations during daylight hours were noted too (Fig. 3b). In summer, peaks in activity were reached at 06:00, at sunrise. Antechinus activity increased two hours before sunset at 18:00 and continued to increase between 21:00 and 22:00. Thus, in summer, antechinus had mostly crepuscular activity patterns (active at twilight). However, in autumn, antechinus activity peaked in the evening one hour after sunset and peaked again two hours before sunrise. Thus, in autumn, antechinus were nocturnal. Nocturnal behaviour was also observed in winter, where peak activity occurred two hours after sunset, then remained relatively constant throughout the night before it peaked again two hours before sunrise. In spring, a return to crepuscular behaviour was observed in antechinus. The first peak in activity occurred within half an hour of sunset, and the second peak occurred one hour before sunrise.

For bush rats, summer had few observations in total $(n=21)$; so any detailed variation in activity throughout the night was limited. Bush rats were mostly uniformly active throughout the night in summer and displayed nocturnal behaviour (most activity occurred at 12:00, Fig. 3c). In autumn, bush rats were predominantly nocturnal with a peak in activity observed between 20:00 and 22:00, before decreased activity occurring two hours before sunrise. In autumn, some observations were recorded during daylight hours. During winter, bush rats exhibited nocturnal behaviour with a marked shift in peaks of activity occurring at 12:00. In winter, bush rat activity was uniform throughout the night, peaking at 01:00.

During summer, brown rat activity was nocturnal and peaked at sunset and only declined at sunrise, indicating in addition to being nocturnal brown rats showed crepuscular behaviour (Fig. 3d). In autumn, brown rats were again nocturnal. Activity peaked two hours after sunset, at 20:00, and declined $2.5 \mathrm{~h}$ before sunrise at 04:00. During winter, brown rats were nocturnal with peaks in activity occurring $2.5 \mathrm{~h}$ after sunset at around 19:30. A second peak in activity was observed for brown rats between 01:00 and 02:00 in winter. During spring, brown rats were nocturnal as observed by their activity throughout the night; however, peaks in activity occurred within one hour after sunset and close to one hour before sunrise, indicating crepuscular behaviours as well.

During summer, brushtail possums were observed beginning their activity at sunset, which continued throughout the night and peaked at one hour before sunrise (Fig. 3e). These activities indicate both nocturnal and crepuscular behaviours during summer. In autumn however, brushtail possum activity was restricted to purely nocturnal hours with a relatively even spread throughout the night, which peaked around 12:00. During winter, brushtail possums were nocturnal with activity peaking two hours after sunset and decreased after 12:00. In spring, brushtail possums showed crepuscular behaviour. Activity peaked within one hour of sunrise and sunset. Nocturnal activity was observed throughout the night except a decline was observed around 12:00.

Southern bobucks during summer reflected distinct nocturnal behaviour with a peak in activity that occurred at around 00:30 (Fig. 3f). During autumn, southern bobuck nocturnal behaviour was again observed with relatively constant activity throughout the night. During winter, bobucks were nocturnal with a peak in activity that occurred three hours after sunset at around 20:00 and beginning to decline after 00:00. During spring, a peak in nocturnal activity was observed for southern bobucks at 23:00.

Ringtail possums exhibited both crepuscular behaviour at sunrise and sunset, with the highest peak of nocturnal activity occurring at 03:00 (Fig. 3g). Limited observations of ringtail possums were made in autumn $(n=12)$; thus, detailed patterns in diel activity are difficult to infer, with a mostly even spread of nocturnal activity throughout the night. During winter, nocturnal observations peaked at around 00:00, with some activity occurring within one hour of sunrise and sunset. Ringtail possums were predominately nocturnal during spring, with a peak in activity at 01:00, with some crepuscular activity observed at within one hour of sunrise.

As not enough observations were made in each season for eastern pygmy possums, data were pooled to produce an annual activity plot (Fig. 4). Pygmy possums were predominately nocturnal (Fig. 4).

\section{Species overlap}

Overlaps in annual diel activities for the eight mammals ranged from 0.66 to 0.93 (Fig. 5). The Mardia-Watson-Wheeler test for differences in activity distributions 


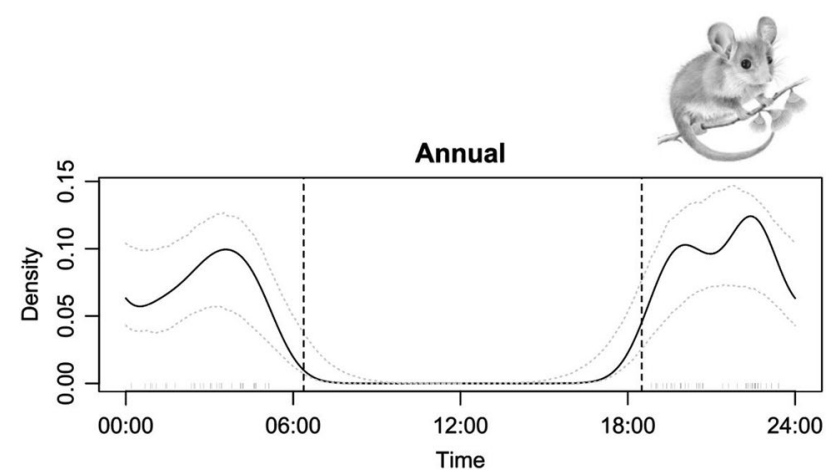

Fig. 4 Annual patterns of diel activity in eastern pygmy possums (Cercartetus nanus). Kernel density activity estimates (y-axis) are shown with $95 \%$ confidence intervals (dotted grey lines). Tick marks on the $x$-axis indicate times of independent observations used to estimate the activity pattern. Black dashed lines are average sunrise and sunset times, calculated for each season. Time depicted is in solar time. Illustration credit: Sarah Hardy (for Blue Roo Inc) indicated that there were significant differences in the activity patterns for 24 of the 28 species comparisons (Fig. 5). The lowest overlap coefficient was between southern bobucks and brown antechinus $(\Delta 4=0.66)$, and their activity curves were significantly different. The highest overlap coefficient was between sugar gliders and brown rats $(\Delta 4=0.93)$; however, despite this high overlap in activity, their activity curves were significantly different.

Brown antechinus activity in areas of high sugar glider activity shifted the timing of their activity peaks, and crepuscular activity, compared to antechinus in areas of low sugar glider activity (Fig. 6a). When sugar gliders were present in high numbers, antechinus shifted their morning peak towards sunrise. Antechinus also shifted their activity to start earlier, before sunset, and greater activity occurred between 15:00 and sunset (Fig. 6a). Where glider abundance was low, antechinus had relatively higher peaks in activity.

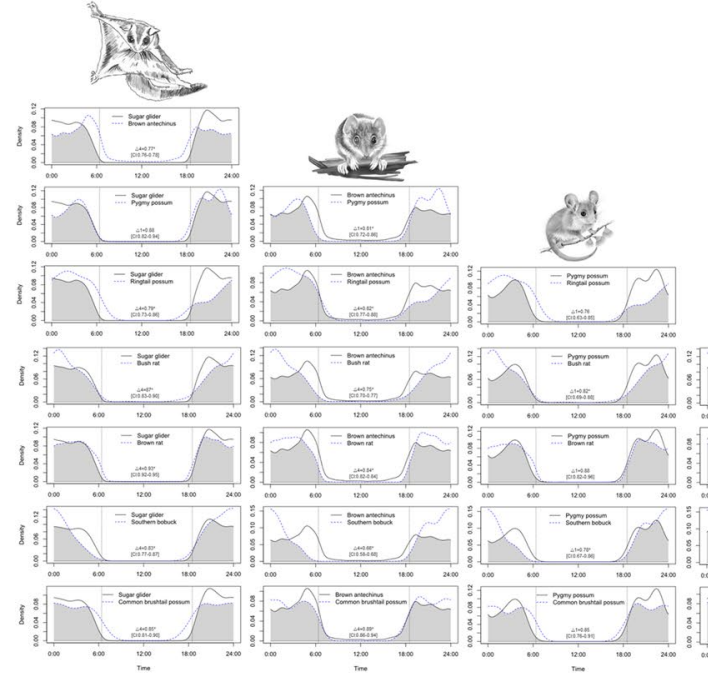

Fig. 5 Kernel density estimates of daily activity patterns and their overlap among pairs of arboreal and semi-arboreal mammals, across one year. Overlap in activity is represented by shaded areas. Dotted lines represent average sunrise and sunset times. Time is displayed in solar time. Significant differences in Mardia-Watson-Wheeler
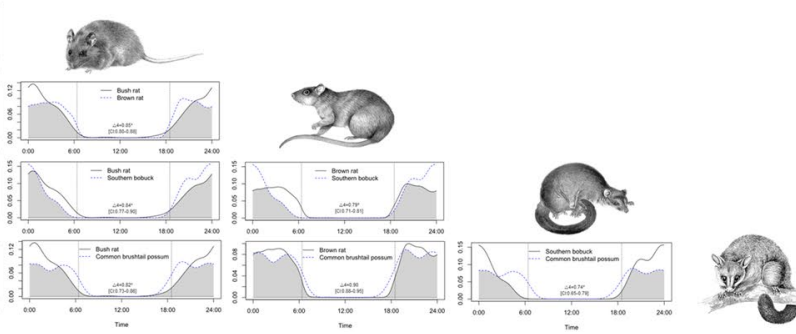

test are indicated by an asterisk after overlap coefficient values $(\Delta)$ Illustration credits for first six images from left to right: Rocco Russo, Tracy MacVean, Sarah Hardy (for Blue Roo Inc), Elizabeth Ann Francis, NSW NPWS, Lizzie Harper www.lizzieharper.co.uk 
Fig. 6 Effect of (a) high and low sugar glider abundance on antechinus behaviour, across one year of activity; and $\mathbf{b}$ high and low brown rat abundance on sugar glider behaviour. Dotted lines represent average sunrise and sunset times. Time is displayed in solar time. Significant differences in Mardia-WatsonWheeler test are indicated by an asterisk after overlap coefficient value $(\Delta)$. Illustration credits: Tracy MacVean and Rocco Russo
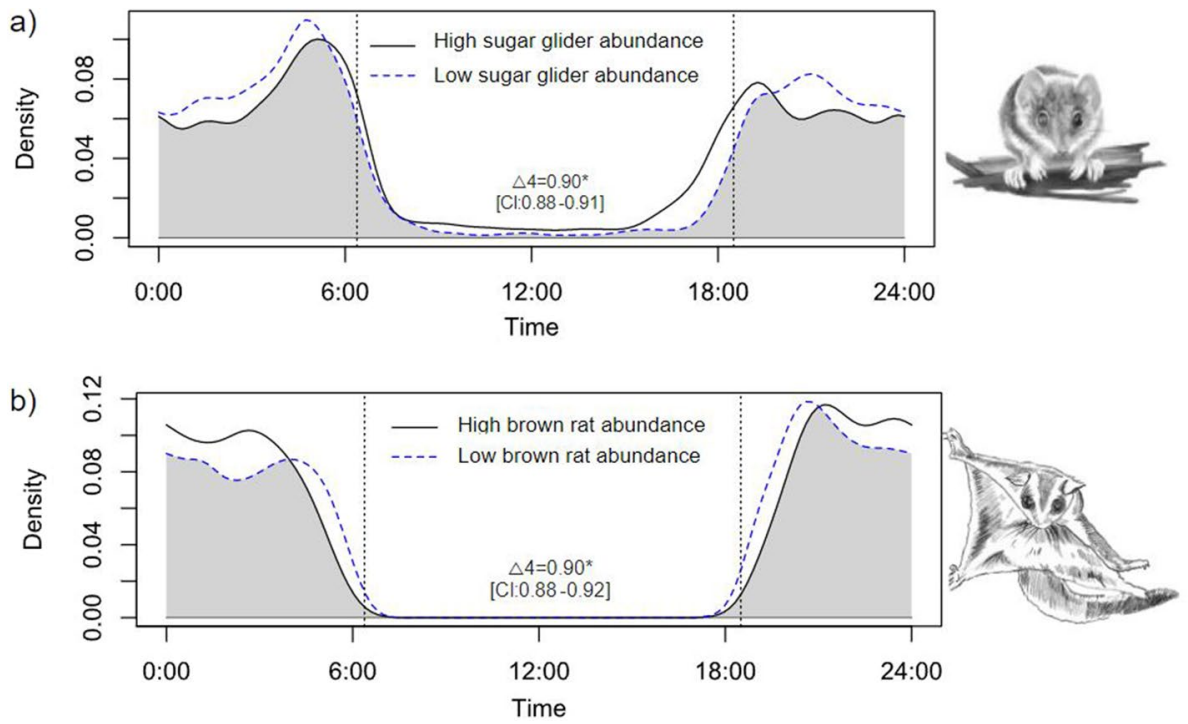

Where brown rats were in high densities, gliders shifted their first peak in activity from 20:30 to 21:00 (Fig. 6b). In the morning, gliders in the presence of high brown rat abundance, shifted their peak of activity from 04:00 to 02:30. There were higher peaks of activity for gliders in areas of high rat abundance compared to gliders from sites of low brown rat abundance.

\section{Behavioural interference}

Interspecific interactions were observed on camera between antechinus and sugar gliders, sugar gliders and brown rats. Antechinus were observed on five videos fleeing from aggressive sugar gliders (on four separate nights). Of the interactions between brown rats and sugar gliders, 12 video observations were antagonistic with gliders immediately fighting and fleeing upon approach by a brown rat (occurring across four separate nights). However, 13 videos recorded observations of coexistence between sub-adult brown rats and sugar gliders (occurring across three separate nights).

\section{Discussion}

\section{Effect of season on activity patterns}

This is the first study to investigate seasonal diel activity of sugar gliders using camera traps. One previous study on radio-collared sugar gliders found gliders were nocturnal with activity beginning at sunset. The onset and decline in activity within a night were found to be determined by temperature and rainfall (Körtner and Geiser 2000). This was also evident in our study where gliders in winter had a delayed start in activity, with overall less activity throughout the night, and ended activity earlier than in other seasons. In summer, the opposite was found with earlier and later activities observed, and more uniform consistent activity throughout the night which could be attributed to more optimal temperatures (Körtner and Geiser 2000).

Antechinus are reported to be mostly nocturnal with daytime activity occurring during the breeding season in winter (Körtner and Geiser 1995; Meek et al. 2012; Gray et al. 2017). Our results were similar; however, we detected distinct peaks in crepuscular activity in summer and spring. We also detected daytime activity throughout all seasons for brown antechinus.

Our study found that bush rats were nocturnal, as reported previously (Wood 1971; Meek et al. 2012), though some daytime activity was observed. Our data suggested mostly unimodal peaks in activity throughout the year, though other studies have found bimodal peaks in activity (Meek et al. 2012). This difference could be attributed to the presence of brown antechinus, as we did not find significant overlap in activity peaks. Sympatric small mammals can show time partitioning to reduce competition for food resources; for example, Meek et al. (2012) found that Rattus luterolus would shift to diurnal foraging in the presence of nocturnal competitors, potentially facilitated through having a competitive edge in terms of eyesight (presence of UV cones). In our study, bush rats could be avoiding competition with sympatric brown antechinus and brown rats.

We found the introduced brown rat was predominately nocturnal with high levels of activity throughout the night, with some increased activity around sunset during the warmer seasons of spring and summer. Similarly, others have reported nocturnality (Calhoun 1963; Knight 1975; Klemann and Pelz 2006). Interestingly, fine-scale variation in behaviour was observed by Klemann and Pelz (2006), 
where brown rats were found to adapt their feeding behaviour to different forms of risk associated with different habitats, and to rapidly shift between diurnal and nocturnal behaviour (Klemann and Pelz 2006). Considering this behavioural plasticity, the study of brown rat ecology in Australian ecosystems and their impact on native species, is of particular interest for conservation and requires further attention.

The brushtail possum is reported to be nocturnal (Isaac 2002) though in our study during warmer months, we detected some crepuscular behaviour at sunrise and sunset. Comparatively, its congener, the southern bobuck, was strictly nocturnal. This could be attributed to the plastic behaviours of brushtail possums in urban and heavily disturbed environments (Eymann et al. 2006). Brushtail possums are capable of inhabiting urban and agricultural landscapes, having adapted to disturbed landscapes and their resources (e.g. using built structures for dens, taking advantage of human sources of food as part of their generalist diet). In comparison, southern bobucks are more specialist as they rely heavily on tree hollows for shelter and Acacia for food (Seebeck et al. 1984). Our limited data for ringtail possums confirm their nocturnality (Isaac 2002). We did record some activity for the species around sunrise and sunset, which has not been reported elsewhere for ringtail possums.

In eastern pygmy possums, previous research has noted nocturnal behaviour, but with seasonal variation as the species is less active in winter when lower temperatures are energetically costly (Harris 2010). Our results confirm nocturnality as well as variation in activity, as we recorded no observations in winter. However, our dataset was limited as selfie traps were not able to detect pygmy possums readily (most observations were opportunistic sightings rather than pygmy possums displaying distinct interest in the bait) and thus we were restricted to estimating annual diel patterns. Our data are the first investigation into the diel activity patterns of the cryptic eastern pygmy possums and provide new insight into the onset of activity occurring around sunset and ending before sunrise.

\section{Overlap in activity}

Sharing limited resources is expected to trigger competition between species (De Boer and Prins 1990) and behavioural adaptions could promote niche partitioning, thereby allowing for species coexistence or sympatry (Razgour et al. 2011; Torretta et al. 2017). In our study, 26/28 pairs of species showed high levels of high overlap $(\Delta>0.75)$. Resource partitioning, as well as spatial partitioning along the vertical axis in space, likely explain the coexistence of many of these species (Schoener 1974; Gloury 2014). Thus, the temporal comparisons of particular interest are those between species that are similar in diet and/or size, as they may indicate temporal avoidance. Ringtail possums, brushtail possums and southern bobucks, are all folivores, though brushtail and ringtail possums have adapted to urban and agricultural landscapes (Eymann et al. 2006; Hill et al. 2007; Russell et al. 2011). These three species have adapted each their own unique foraging niche through resource partitioning (Gloury 2014).

Differences in activity curves between brushtail possums and southern bobucks, both from the same genus, are likely explained by the exploitative behaviours of the more common brushtail possum (far more activity during crepuscular and daylight times). Southern bobucks were recorded north of the major highway in larger patches of forest only, predominately in the remote subtropical rainforest of the Illawarra Escarpment. Thus, bobucks in this undisturbed landscape could be considered more specialised and 'timid' compared to brushtail possum. Similarly, the overlap of these two species with ringtails indicated no competition or avoidance. The bait inside the selfie traps was not consumed by ringtail possums, instead it is thought that they were entering to assess its use as a den (on multiple occasions possums were observed sleeping inside during the day). Thus, for these possum species, our data provide some of the first investigation into seasonal effects, and the overlap comparisons reveal species-specific behaviours and not competition.

Another overlap comparison of interest is between bush rats, brown rats, and brown antechinus. All three species show semi-arboreal behaviour though they are predominately terrestrial (brown rat is the least arboreal, antechinus the most arboreal), and all have some dietary overlap (Watts and Braithwaite 1978; Hall 1980; Cheal 1987). The brown rat is an invasive species and no ecological study of brown rats exists for Australia (Vadell et al. 2014). Thus, its impact on native species has not been evaluated, and in our study, the species only occurred in disturbed habitat (on farms). Interestingly, antechinus and bush rats (both native), displayed differences in activity peaks compared to brown rats. The most prominent difference in these peaks, however was observed between the two native species that co-evolved. Bush rats had peaks in activity around midnight compared to the mostly crepuscular peaks in antechinus activity. Studies on other small mammal guilds, have also found patterns of time partitioning, hypothesised to occur to reduce competition for food resources (Kotler et al. 1993; Meek et al. 2012).

\section{Effect of sugar gliders on antechinus behaviour}

The overlap between sugar gliders and antechinus was significant. Potential competitors that are morphologically similar or closely related tend to develop behaviours to alleviate competition and behavioural interference (Schoener 1974). 
Both species were recorded in high numbers (sugar gliders were observed on average 2.63 per camera trap night; and brown antechinus were observed 1.88 times per camera trap night). Thus, as the dominant visitors to the resources provided by the selfie trap (food and shelter), antechinus may be shifting their behaviour to avoid sugar gliders. This hypothesis is based on the observations that antechinus are significantly smaller and displayed fear on camera of gliders. Other studies have also found a size relationship to avoidance, where smaller species generally avoid larger and thus more dominant species (Persson 1985; Ziv et al. 1993; French and Smith 2005). Besides pygmy possums, antechinus are the most comparable to sugar gliders regarding scansorial behaviour among the small mammals in this study (observations of antechinus occurring at $12.8 \mathrm{~m}$ in the canopy at the study site; M. Hoffman pers. comm.). Additionally, Petaurus species though primarily insectivorous/nectarivorous, have been recorded preying on birds (Winter 1966; Holland 2001; Stojanovic et al. 2014). Furthermore, predatory behaviours of gliders in captivity have been observed when offered live mice (Fleay 1954); thus, gliders could opportunistically prey on antechinus in the wild. Risk of aggression can cause species to alter the timing of their activity to reduce interactions with competitors (Polis et al. 1989). Sugar gliders are social animals and scent mark their territory using glands located on their chest and foreheads (Schultze-Westrum 1969; Nowak 2018). We observed gliders in our study actively scent marking the selfie trap; however, glider scent marking is also passive and occurs throughout their nightly activity as they move on tree branches and leaves (Schultze-Westrum 1969; Nowak 2018). Thus, in response to high glider abundance, possible predation risk and strong scents left by gliders inside selfie traps, antechinus may have shifted to more crepuscular and daylight activity. The highest peak of antechinus activity occurred closer to sunrise which could be aiding their behaviour to avoid the peak in activity of gliders after sunrise.

\section{Effect of brown rats on sugar glider behaviour}

Further potential competition-mediated changes in activity are observed between brown rats and sugar gliders. Brown rats also have scent marking procedures through urinating and flank marking (Peden and Timberlake 1990) and they were often seen defecating inside selfie traps. The strong scent and presence of high abundance brown rats at certain sites, may have contributed to the observed shifts in sugar glider behaviour to avoid brown rats. Sugar gliders are smaller than brown rats and could be avoiding the dominance and aggression from brown rats at the bait stations. Brown rats were found to display crepuscular and nocturnal behaviours in summer and spring; thus, gliders may have shifted their behaviour to avoid crepuscular times when brown rats were active. However, there were observations of coexistence between brown rats, and these were of sub-adults that were closer in size to sugar gliders. In this situation, we hypothesise that the cost of aggression is far higher in individuals of similar size as risk of severe injury or mortality is higher. Animals must find a balance between the costs associated with interspecific competition and the costs of resource acquisition (Armstrong and McGehee 1976; Ferry et al. 2016; Lea et al. 2018).

\section{Conclusion}

In summary, though most pairs of species showed high levels of activity overlap, species with similar diets or similar in size segregated many of their activity peaks during a diel cycle which suggests some avoidance to decrease competition, and the risk of aggression. Our study is the first to quantify cathemeral activity patterns for several species in this study and to investigate the impact of season on these patterns. Additionally, we were able to explore the potential influence of observed behavioural interference in explaining shifts in activity.

Supplementary Information The online version contains supplementary material available at https://doi.org/10.1007/s42991-021-00218-y.

Acknowledgements We acknowledge the Dharawal people, the traditional custodians of the land, and pay our respects to elders past, present and emerging. A massive thank you to all the volunteers who assisted with fieldwork, and to the private landholders for allowing us to do research on their properties.

Author contributions $\mathrm{AG}$ and $\mathrm{KM}$ conceived the ideas and designed methodology; AG collected the data; AG analysed the data; AG and KM led the writing of the manuscript.

Funding Open Access funding enabled and organized by CAUL and its Member Institutions. Fieldwork was supported by a SMAH Partnership grant with NSW National Parks Association and Berry Wildlife Corridor (NSW Environment Trust).

Availability of data and materials The datasets generated during the current study are available from the corresponding authors on reasonable request.

Code availability The code generated during the current study is available from the corresponding authors on reasonable request.

\section{Declarations}

Conflict of interest The authors declare no conflicts of interest.

Ethics approval This work was conducted under NSW DPIE Scientific Licence 101968 and UOW Animal Ethics protocol AE1902.

Consent to participate Not applicable. 
Consent for publication Not applicable.

Open Access This article is licensed under a Creative Commons Attribution 4.0 International License, which permits use, sharing, adaptation, distribution and reproduction in any medium or format, as long as you give appropriate credit to the original author(s) and the source, provide a link to the Creative Commons licence, and indicate if changes were made. The images or other third party material in this article are included in the article's Creative Commons licence, unless indicated otherwise in a credit line to the material. If material is not included in the article's Creative Commons licence and your intended use is not permitted by statutory regulation or exceeds the permitted use, you will need to obtain permission directly from the copyright holder. To view a copy of this licence, visit http://creativecommons.org/licenses/by/4.0/.

\section{References}

Ables ED (1969) Activity studies of red foxes in southern Wisconsin. J Wildl Manag 33:145-153

Abu Baker MA, Brown JS (2014) Foraging in space and time structure an African small mammal community. Oecologia 175:521-535. https://doi.org/10.1007/s00442-014-2926-6

Agha M, Batter T, Bolas EC et al (2018) A review of wildlife camera trapping trends across Africa. Afr J Ecol 56:694-701. https://doi. org/10.1111/aje.12565

Agostinelli C, Lund U (2017) R package 'circular': circular statistics (version 0.4-93). Department of Environmental Sciences, Informatics and Statistics, CA, https://r-forge.r-project.org/projects/ circular/

Altizer S, Bartel R, Han BA (2011) Animal migration and infectious disease risk. Science (80-) 331:296-302

Andreoni A, Augugliaro C, Zozzoli R et al (2021) Diel activity patterns and overlap between Eurasian red squirrels and Siberian chipmunks in native and introduced ranges. Ethol Ecol Evol 33:83-89. https://doi.org/10.1080/03949370.2020.1777211

Armstrong RA, McGehee R (1976) Coexistence of species competing for shared resources. Theor Popul Biol 9:317-328

Barrull J, Mate I, Ruiz-Olmo J et al (2014) Factors and mechanisms that explain coexistence in a Mediterranean carnivore assemblage: an integrated study based on camera trapping and diet. Mamm Biol 79:123-131. https://doi.org/10.1016/j.mambio.2013. 11.004

Belovsky GE, Slade JB (1986) Time budgets of grassland herbivores: body size similarities. Oecologia 70:53-62

Bennie JJ, Duffy JP, Inger R, Gaston KJ (2014) Biogeography of time partitioning in mammals. Proc Natl Acad Sci USA 111:1372713732. https://doi.org/10.1073/pnas. 1216063110

Berger KM, Gese EM (2007) Does interference competition with wolves limit the distribution and abundance of coyotes? J Anim Ecol 76:1075-1085

Bonnot NC, Couriot O, Berger A et al (2020) Fear of the dark? Contrasting impacts of humans versus lynx on diel activity of roe deer across Europe. J Anim Ecol 89:132-145. https://doi.org/ $10.1111 / 1365-2656.13161$

Bridges AS, Noss AJ (2011) Behavior and activity patterns. Camera traps in animal ecology. Springer, Tokyo, pp 57-69

Burton AC, Neilson E, Moreira D et al (2015) Wildlife camera trapping: a review and recommendations for linking surveys to ecological processes. J Appl Ecol 52:675-685

Calhoun JB (1963) The ecology and sociology of the Norway rat. US Department of Health Education, and Welfare, Public Health Service, Bethesda
Caravaggi A, Banks PB, Burton AC et al (2017) A review of camera trapping for conservation behaviour research. Remote Sens Ecol Conserv 3:109-122. https://doi.org/10.1002/rse2.48

Caravaggi A, Gatta M, Vallely M-C et al (2018) Seasonal and predator-prey effects on circadian activity of free-ranging mammals revealed by camera traps. PeerJ 6:e5827

Carothers JH, Jaksić FM (1984) Time as a niche difference: the role of interference competition. Oikos 42:403-406

Carscadden KA, Emery NC, Arnillas CA et al (2020) Niche breadth: causes and consequences for ecology, evolution, and conservation. Q Rev Biol 95:179-214

Case TJ, Gilpin ME (1974) Interference competition and niche theory. Proc Natl Acad Sci 71:3073-3077

Cheal DC (1987) The diets and dietary preferences of Rattus-Fuscipes and Rattus-Lutreolus at Walkerville in Victoria. Wildl Res $14: 35-44$

Cunningham CX, Scoleri V, Johnson CN et al (2019) Temporal partitioning of activity: rising and falling top-predator abundance triggers community-wide shifts in diel activity. Ecography (cop) 42:2157-2168. https://doi.org/10.1111/ecog.04485

Daan S (1981) Adaptive daily strategies in behavior. Biological rhythms. Springer, Berlin, pp 275-298

De Boer WF, Prins HHT (1990) Large herbivores that strive mightily but eat and drink as friends. Oecologia 82:264-274

Delisle ZJ, Flaherty EA, Nobbe MR et al (2021) Next-generation camera trapping: systematic review of historic trends suggests keys to expanded research applications in ecology and conservation. Front Ecol Evol 9:97

Dickman CR (1991) Mechanisms of competition among insectivorous mammals. Oecologia 85:464-471. https://doi.org/10.1007/ BF00323757

Eymann J, Herbert CA, Cooper DW (2006) Management issues of urban common brushtail possums Trichosurus vulpecula: a loved or hated neighbour. Aust Mammal 28:153-171

Ferry N, Dray S, Fritz H, Valeix M (2016) Interspecific interference competition at the resource patch scale: do large herbivores spatially avoid elephants while accessing water? J Anim Ecol 85:1574-1585

Fleay D (1954) The squirrel glider. Vic Nat 70:208-210

French AR, Smith TB (2005) Importance of body size in determining dominance hierarchies among diverse tropical frugivores 1 . Biotropica J Biol Conserv 37:96-101

Frey S, Fisher JT, Burton AC, Volpe JP (2017) Investigating animal activity patterns and temporal niche partitioning using cameratrap data: challenges and opportunities. Remote Sens Ecol Conserv 3:123-132

Gashe T, Yihune M (2020) Population status, foraging ecology and activity pattern of golden jackal (Canis aureus) in Guangua Ellala Forest, Awi Zone, north west Ethiopia. PLoS One 15:e0233556

Gaudiano L, Pucciarelli L, Mori E (2021) Livestock grazing affects movements and activity pattern of Italian roe deer in Southern Italy. Eur J Wildl Res 67:66. https://doi.org/10.1007/ s10344-021-01506-1

Gaynor KM, Hojnowski CE, Carter NH, Brashares JS (2018) The influence of human disturbance on wildlife nocturnality. Science (80-) 360:1232-1235

GER (2021) The Great Eastern Ranges. https://ger.org.au/. Accessed 23 Mar 2021

Gloury AM (2014) Competition and coexistence: the ecology of sympatric common and mountain brushtail possums (Trichosurus spp.). University of Melbourne, Melbourne Honours thesis

Gómez H, Wallace RB, Ayala G, Tejada R (2005) Dry season activity periods of some Amazonian mammals. Stud Neotrop Fauna Environ 40:91-95. https://doi.org/10.1080/01650520500129638 
Gracanin A, Gracanin V, Mikac KM (2018) The selfie trap: a novel camera trap design for accurate small mammal identification. Ecol Manag Restor. https://doi.org/10.1111/emr.12345

Gray EL, Dennis TE, Baker AM (2017) Can remote infrared cameras be used to differentiate small, sympatric mammal species? A case study of the black-tailed dusky antechinus, Antechinus arktos and co-occurring small mammals in southeast Queensland. Australia Plos One 12:e0181592. https://doi.org/10.1371/journ al.pone. 0181592

Hall S (1980) The diets of two coexisting species of Antechinus (Marsupialia: Dasyuridae). Wildl Res 7:365-378

Halle S, Stenseth NC (2012) Activity patterns in small mammals: an ecological approach. Springer, Berlin

Hanya G, Otani Y, Hongo S et al (2018) Activity of wild Japanese macaques in Yakushima revealed by camera trapping: Patterns with respect to season, daily period and rainfall. PLoS One 13:e0190631

Harrington LA, Harrington AL, Yamaguchi N et al (2009) The impact of native competitors on an alien invasive: temporal niche shifts to avoid interspecific aggression. Ecology 90:1207-1216

Harris JM (2010) The natural history, conservation status and ecology of the eastern pygmy-possum (Cercartetus nanus). Southern Cross University, Lismore $\mathrm{PhD}$ Thesis

Harvell D, Altizer S, Cattadori IM et al (2009) Climate change and wildlife diseases: when does the host matter the most? Ecology 90:912-920

Hayward MW, Slotow R (2009) Temporal partitioning of activity in large African carnivores: tests of multiple hypotheses. South African J Wildl Res Delayed Open Access 39:109-125

Hertel AG, Swenson JE, Bischof R (2017) A case for considering individual variation in diel activity patterns. Behav Ecol 28:15241531. https://doi.org/10.1093/beheco/arx122

Hill NJ, Carbery KA, Deane EM (2007) Human-possum conflict in urban Sydney, Australia: public perceptions and implications for species management. Hum Dimens Wildl 12:101-113. https:// doi.org/10.1080/10871200701195928

HilleRisLambers J, Adler PB, Harpole WS et al (2012) Rethinking community assembly through the lens of coexistence theory. Annu Rev Ecol Evol Syst 43:227-248

Hobbs MT, Brehme CS (2017) An improved camera trap for amphibians, reptiles, small mammals, and large invertebrates. PLoS ONE 12:1-15. https://doi.org/10.1371/journal.pone.0185026

Holland G (2001) Opportunistic vertebrate predation by the squirrel glider Petaurus norfolcensis. Vic Nat 118:123-126

Huck M, Juárez CP, Fernández-Duque E (2017) Relationship between moonlight and nightly activity patterns of the ocelot (Leopardus pardalis) and some of its prey species in Formosa, Northern Argentina. Mamm Biol 82:57-64. https://doi.org/10.1016/j.mambio.2016.10.005

Hughes JJ, Ward D, Perrin MR (1994) Predation risk and competition affect habitat selection and activity of Namib Desert gerbils. Ecology 75:1397-1405

Ikeda T, Uchida K, Matsuura Y et al (2016) Seasonal and diel activity patterns of eight sympatric mammals in northern Japan revealed by an intensive camera-trap survey. PLoS One 11:1-16. https:// doi.org/10.1371/journal.pone.0163602

Isaac JL (2002) Kerle A, 2001. Possums: the brushtails, ringtails and greater glider. Aust Mammal 24:249

Kavčić K, Radočaj T, Corlatti L, et al (2021) Spatio-temporal response of forest-dwelling chamois to red deer presence. Mamm Biol 1-9

Kays R, Allison A (2001) Arboreal tropical forest vertebrates: current knowledge and research trends. In: Linsenmair KE, Davis AJ, Fiala B, Speight MR (eds) Tropical forest canopies: ecology and management. Forestry Sciences, vol 69. Springer, Dordrecht. https://doi.org/10.1007/978-94-017-3606-0_9
Klemann N, Pelz HJ (2006) The feeding pattern of the Norway rat (Rattus norvegicus) in two differently structured habitats on a farm. Appl Anim Behav Sci 97:293-302

Knight DA (1975) Some aspects of the daily activity of the water vole, arvicola terrestris linn, and the brown rat, rattus norvegicus linn, Durham theses, Durham University. Available at Durham E-Theses Online: http://etheses.dur.ac.uk/9050/

Körtner G, Geiser F (1995) Body temperature rhythms and activity in reproductive Antechinus (Marsupialia). Physiol Behav $58: 31-36$

Körtner G, Geiser F (2000) Torpor and activity patterns in free-ranging sugar gliders Petaurus breviceps (Marsupialia). Oecologia 123:350-357. https://doi.org/10.1007/s004420051021

Kotler BP, Brown JS, Subach A (1993) Mechanisms of species coexistence of optimal foragers: temporal partitioning by two species of sand dune gerbils. Oikos 67:548-556

Kronfeld-Schor N, Dayan T (2003) Partitioning of time as an ecological resource. Annu Rev Ecol Evol Syst 34:153-181. https://doi.org/ 10.1146/annurev.ecolsys.34.011802.132435

Lashley MA, Cove MV, Chitwood MC et al (2018) Estimating wildlife activity curves: comparison of methods and sample size. Sci Rep $8: 1-11$

Lea JSE, Daly R, Leon C et al (2018) Life after death: Behaviour of multiple shark species scavenging a whale carcass. Mar Freshw Res 70:302-306

Lear KO, Whitney NM, Morris JJ, Gleiss AC (2021) Temporal niche partitioning as a novel mechanism promoting co-existence of sympatric predators in marine systems. Proc R Soc B 288:20210816

Leo V, Reading RP, Letnic M (2015) Interference competition: odours of an apex predator and conspecifics influence resource acquisition by red foxes. Oecologia 179:1033-1040. https://doi.org/10. 1007/s00442-015-3423-2

Li J, Xue Y, Zhang Y et al (2020) Spatial and temporal activity patterns of Golden takin (Budorcas taxicolor bedfordi) recorded by camera trapping. PeerJ 8:1-18. https://doi.org/10.7717/peerj.10353

Marinho PH, Fonseca CR, Sarmento P et al (2020) Temporal niche overlap among mesocarnivores in a Caatinga dry forest. Eur J Wildl Res. https://doi.org/10.1007/s10344-020-1371-6

McCleery RA, Zweig CL, Desa MA et al (2014) A novel method for camera-trapping small mammals. Wildl Soc Bull 38:887-891. https://doi.org/10.1002/wsb.447

Meek PD, Zewe F, Falzon G (2012) Temporal activity patterns of the swamp rat (Rattus lutreolus) and other rodents in north-eastern New South Wales, Australia. Aust Mammal 34:223-233. https:// doi.org/10.1071/AM11032

Meek PD, Vernes K, Falzon G (2013) On the reliability of expert identification of small-medium sized mammals from camera trap photos. Wildl Biol Pract 9:1-19. https://doi.org/10.2461/ wbp.2013.9.4

Moore JF, Soanes K, Balbuena D et al (2021) The potential and practice of arboreal camera trapping. Methods Ecol Evol. https://doi. org/10.1111/2041-210X.13666

Mori E, Ferretti F, Fattorini N (2019) Alien war: ectoparasite load, diet and temporal niche partitioning in a multi-species assembly of small rodents. Biol Invasions 21:3305-3318. https://doi.org/10. 1007/s10530-019-02048-z

Mori E, Andreoni A, Cecere F et al (2020) Patterns of activity rhythms of invasive coypus Myocastor coypus inferred through cameratrapping. Mamm Biol 100:591-599. https://doi.org/10.1007/ s42991-020-00052-8

Mori E, Paniccia C, Munkhtsog B et al (2021) Temporal overlap among small- and medium-sized mammals in a grassland and a forest-alpine meadow of Central Asia. Mamm Biol 101:153-162. https://doi.org/10.1007/s42991-020-00085-z 
Mos J, Hofmeester TR (2020) The Mostela: an adjusted camera trapping device as a promising non-invasive tool to study and monitor small mustelids. Mammal Res 65:843-853

Mukherjee S, Zelcer M, Kotler BP (2009) Patch use in time and space for a meso-predator in a risky world. Oecologia 159:661-668. https://doi.org/10.1007/s00442-008-1243-3

Mutschler T, Freistner ATC, Nievergelt CM (1998) Preliminary field data on group size, diet and activity in the Alaotran gentle lemur Hapalemur griseus alaotrensis. Folia Primatol 69:325

Nguyen HN, Hung C-M, Yang M-Y, Lin S-M (2020) Sympatric competitors have driven the evolution of temporal activity patterns in Cnemaspis geckos in Southeast Asia. Sci Rep 10:27. https:// doi.org/10.1038/s41598-019-56549-x

Niedballa J, Sollmann R, Courtiol A, Wilting A (2016) camtrapR: an $\mathrm{R}$ package for efficient camera trap data management. Methods Ecol Evol 7:1457-1462. https://doi.org/10.1111/2041-210X. 12600

Nowak RM (2018) Walker's mammals of the world: monotremes, marsupials, afrotherians, xenarthrans, and sundatherians. JHU Press, Baltimore

Oliveira-Santos LGR, Tortato MA, Graipel ME (2008) Activity pattern of Atlantic Forest small arboreal mammals as revealed by camera traps. J Trop Ecol 24:563-567. https://doi.org/10.1017/ S0266467408005324

Pascual-Rico R, Sánchez-Zapata JA, Navarro J et al (2020) Ecological niche overlap between co-occurring native and exotic ungulates: insights for a conservation conflict. Biol Invasions 22:2497-2508

Peden BF, Timberlake W (1990) Environmental influences on flank marking and urine marking by female and male rats (Rattus norvegicus). J Comp Psychol 104:122

Pereira JA (2010) Activity pattern of Geoffroy's cats (Leopardus geoffroyi) during a period of food shortage. J Arid Environ 74:11061109. https://doi.org/10.1016/j.jaridenv.2010.03.017

Persson L (1985) Asymmetrical competition: are larger animals competitively superior? Am Nat 126:261-266

Ping X, Li C, Jiang Z et al (2011) Interference competition and group size effect in sika deer (Cervus nippon) at salt licks. Acta Ethol 14:43-49. https://doi.org/10.1007/s10211-011-0092-y

Polis GA, Myers CA, Holt RD (1989) The ecology and evolution of intraguild predation: potential competitors that eat each other. Annu Rev Ecol Syst 20:297-330

Porfirio G, Sarmento P, Foster V, Fonseca C (2017) Activity patterns of jaguars and pumas and their relationship to those of their potential prey in the Brazilian Pantanal. Mammalia 81:401-404. https://doi.org/10.1515/mammalia-2015-0175

Potter LC, Brady CJ, Murphy BP (2019) Accuracy of identifications of mammal species from camera trap images: a northern Australian case study. Austral Ecol 44:473-483. https://doi.org/10. $1111 /$ aec. 12681

R Core Team (2021) R: A language and environment for statistical computing. http://www.R-project.org/. In: R Found. Stat. Comput. Vienna, Austria

Razgour O, Korine C, Saltz D (2011) Does interspecific competition drive patterns of habitat use in desert bat communities? Oecologia 167:493-502

Ridout MS, Linkie M (2009) Estimating overlap of daily activity patterns from camera trap data. J Agric Biol Environ Stat 14:322337. https://doi.org/10.1198/jabes.2009.08038

Romero-Munoz A, Maffei L, Cuéllar E, Noss AJ (2010) Temporal separation between jaguar and puma in the dry forests of southern Bolivia. J Trop Ecol 26:303-311

Roth HU (1983) Diel activity of a remnant population of European brown bears. Bears Their Biol Manag 5:223-229

Rowcliffe JM, Kays R, Kranstauber B et al (2014) Quantifying levels of animal activity using camera trap data. Methods Ecol Evol 5:1170-1179. https://doi.org/10.1111/2041-210x.12278
Russell TC, Bowman BR, Herbert CA, Kohen JL (2011) Suburban attitudes towards the common brushtail possum Trichosurus vulpecula and the common ringtail possum Pseudocheirus peregrinus in the northern suburbs of Sydney. Aust Zool 35:888-894. https://doi.org/10.7882/AZ.2011.043

Rychlik L (2005) Overlap of temporal niches among four sympatric species of shrews. Acta Theriol (warsz) 50:175-188. https://doi. org/10.1007/BF03194481

Saleni P, Gusset M, Graf JA et al (2007) Refuges in time: temporal avoidance of interference competition in endangered wild dogs Lycaon pictus. Canid News 10:1-5

Schoener TW (1974) Resource partitioning in ecological communities. Science (80-) 185:27-39

Schultze-Westrum TG (1969) Social communication by chemical signals in flying phalangers (Petaurus breviceps papuanus). Olfaction Tast 3:268-277

Seebeck JH, Warneke RM, Baxter BJ (1984) Diet of the bobuck, Trichosurus caninus (Ogilby) (Marsupialia: Phalangeridae) in a mountain forest in Victoria. In: Smith AP, Hume ID (eds) Possums and Gliders. Australian Mammal Society, Sydneypp, pp $145-154$

Shamoon H, Maor R, Saltz D, Dayan T (2018) Increased mammal nocturnality in agricultural landscapes results in fragmentation due to cascading effects. Biol Conserv 226:32-41. https://doi. org/10.1016/j.biocon.2018.07.028

Sofer N (2021) Bulk file changer. https://www.nirsoft.net/utils/bulk_ file_changer.html. Accessed 11 Apr 2021

Šprem N, Zanella D, Ugarković D et al (2015) Unimodal activity pattern in forest-dwelling chamois: typical behaviour or interspecific avoidance? Eur J Wildl Res 61:789-794. https://doi.org/10.1007/ s10344-015-0939-z

Stojanovic D, Webb MH, Alderman R et al (2014) Discovery of a novel predator reveals extreme but highly variable mortality for an endangered migratory bird. Divers Distrib 20:1200-1207

Suzuki KK, Ando M (2017) Seasonal changes in activity patterns of Japanese flying squirrel Pteromys momonga. Behav Process 143:13-16. https://doi.org/10.1016/j.beproc.2017.08.003

Suzuki KK, Ando M (2019) Effect of rainfall on nocturnal activity of the Japanese dormouse. Clim Res 78:205-209. https://doi.org/ $10.3354 / \mathrm{cr} 01570$

Torretta E, Mosini A, Piana M et al (2017) Time partitioning in mesocarnivore communities from different habitats of NW Italy: insights into martens' competitive abilities. Behaviour 154:241-266

Turner V (1984) Banksia pollen as a source of protein in the diet of two australian marsupials Cercartetus nanus and Tarsipes rostratus. Oikos 43:53-61. https://doi.org/10.2307/3544245

Vadell MV, Villafañe IEG, Cavia R (2014) Are life-history strategies of Norway rats (Rattus norvegicus) and house mice (Mus musculus) dependent on environmental characteristics? Wildl Res 41:172-184

Vazquez C, Rowcliffe JM, Spoelstra K, Jansen PA (2019) Comparing diel activity patterns of wildlife across latitudes and seasons: time transformations using day length. Methods Ecol Evol 10:2057-2066. https://doi.org/10.1111/2041-210X.13290

Watts CHS, Braithwaite RW (1978) The diet of Rattus lutreolus and five other rodents in southern Victoria. Wildl Res 5:47-57

Williams CT, Buck CL, Sheriff MJ et al (2017) Sex-dependent phenological plasticity in an arctic hibernator. Am Nat 190:854-859

Winter JW (1966) Bird predation by the Australian marsupial Squirrel Glider. J Mammal 47:530

Wood DH (1971) The ecology of Rattus fuscipes and Melomys cervinipes (Rodentia: Muridaae) in a south-east Queensland rain forest. Aust J Zool 19:371-392 
Wrobell DJ, Gergits WF, Jaeger RG (1980) An experimental study of interference competition among terrestrial salamanders. Ecology 61:1034-1039. https://doi.org/10.2307/1936820

Wu Y, Wang H, Wang H, Feng J (2018) Arms race of temporal partitioning between carnivorous and herbivorous mammals. Sci Rep 8:1-9. https://doi.org/10.1038/s41598-018-20098-6

Yang LH, Rudolf VHW (2010) Phenology, ontogeny and the effects of climate change on the timing of species interactions. Ecol Lett 13:1-10

Yang Y, Lei X, Yang C (2002) Ecology of the wild Guizhou snubnosed monkey. Guizhou Sci Technol Press Guiyang, China
Ziv Y, Abramsky Z, Kotler BP, Subach A (1993) Interference competition and temporal and habitat partitioning in two gerbil species. Oikos 66:237-246

Publisher's Note Springer Nature remains neutral with regard to jurisdictional claims in published maps and institutional affiliations. 